\title{
Challenges to the current provision of mental health services and development of psychiatry in Africa
}

\author{
Dr Fred N Kigozi is Senior Consultant Psychiatrist and Medic al Director, Buta bika \\ National Referral Mental Hospital, Kampala, Uganda, President of the Uganda \\ Psychiatric Association, and Zonal Representative, WPA Zone 14. He was formerly \\ Senior Lec turer in the Department of Psychiatry, Makerere Medical School.
}

The history of the development of mental health services in A frica falls into four phases, firstly the pre-colonial phase, with care being under the traditional and spiritual healers, then the rise of asylums for mainly custodial confinement, followed by modern large asylum-like mental hospitals during and soon after the colonial period, and most recently the decentralisation of mental health care and adoption of $W$ orld Health 0 rganisation recommendations and the Alma Ata concept by integrating mental health into general health care during the last two decades or so. The concept of community care as it is known in the $W$ est has yet to permeate the African continent.

\section{Cument trends}

Despite rapid recent advances in knowledge and the evidencebased approach in the developed countries, especially in the $W$ estern world, services in many countries in Africa remain underdeveloped with a large imbalance between urban and rural communities. It is equally sad to note that the first phrase of the historical process described above still prevails in almost all the rural areas in Africa, where traditional care based on local healers remains the point of first contact for most patients. W hat has gone wrong in Africa?

A review of the mental health programmes in Africa indicates that most countries in the region have had a decentralisation policy for mental health services in place for quite some time, and equally that a large number have embraced the policy of integration of mental health services into general health as the most effective way to deliver services to those in need in an attempt to address issues of equity and access to mental health interventions.

Reprinted from a recent African Association new sletter for the regional representative of the $W$ orld Psychiatric Association.

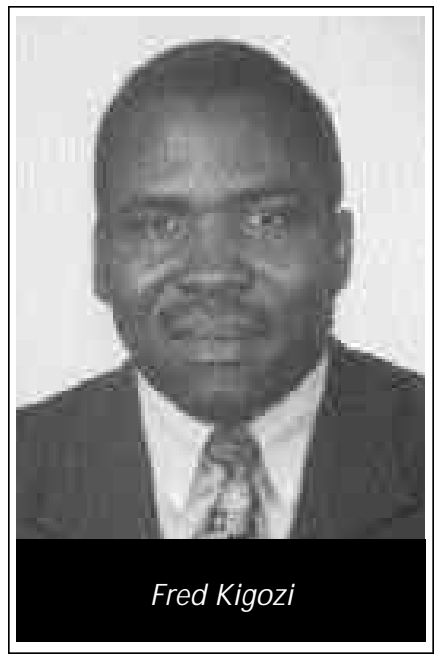

$0 \mathrm{n}$ the other hand, the situation on the ground usually does not reflect the nice policies and programmes in the statutes and health policies. Decentralisation has remained highly specialised, with no community approach and hardly any liaison service offered. The situation therefore appears to have perpetuated stigmatisation and restriction of our clients to accessing modern psychiatric interventions, though there has been improvement in coverage away from the traditional large mental hospitals. M ental health services in general have continued to be accorded a very low priority and consequently minimal resource allocation. Many psychiatrists and other mental health workers on the African continent concur with 0 kasha's observations on the major constraints to the development of mental health services, especially in the sub-Saharan region, namely:

- Lack of awareness of the magnitude of the problem with the very limited epidemiological studies available.

- $N$ on-a vailability of a reliable information management system, 
resulting in lack of reliable data. As a result, efficient and costeffective forms of available interventions cannot be shared among the scattered mental health workers.

- Inadequate human and financial resources has become a 'normal' situation in the area of mental health.

- Absence of or out of date mental health policies and laws.

- Constant departure or brain drain of well-trained and specialised personnel looking for 'greener pastures' in the apparent safety of the $W$ est.

- W idespread civil strife and violence in many of the countries in Africa, contributing to a high prevalence of psychiatric morbidity and mortality as a result of displacement, malnutrition and psychotrauma.

In the last decade or so, the arrival on the scene of HIV/ AIDS under these circumstances has caused further havoc in the worst affected communities, which are already living marginally or below the poverty line, perpetuating the vicious cycle of poverty and disease.

In spite of the above scenario, there is a lot of optimism among many of the leaders in the psychiatric field in many of the African countries today. There is renewed enthusiasm and tea mw ork, and we therefore hope and believe that with determination of many enlighted psychiatrists and other mental health workers to get to gether to continually review what has gone wrong, to share knowledge and skills, to lobby their individual governments, and to promote appropriate training for graduate psychiatrists, many of the problems hindering the development of psychiatry in our region will be overcome. The revival of regional professional groupings among the fraternity and the recent rebirth of the Association of African Psychiatrists and Allied Professionals appears to be a step in the right direction.

\section{The way forward}

$W$ hat then is the way forward? The theme for the 2002 Congress of the Society of Psychiatrists of South A frica, 'The Psychiatrist, the Patient and the Community', in my view suggests the right direction as we ponder the future development of psychiatry in Africa. We can also take inspiration from the assertion of Lopez-lbor Junior (2002) that 'Psychiatry cannot continue to fight against adverse social conditions or phenomena which appear to sustain or aggrava te mental diseases. It should advocate, with scientific evidence, for change in the environment.' This can only be achieved by reexamining the relationship between the psychiatrist, the patient and the community. It will also require the building of partnerships with other sectors of society in order to promote mental health, prevent psychiatric disorders and improve treatment modalities. In essence, a mixed grill of intervention programmes that have cultural and realistic economic relevance to Africa should be advocated from the numerous international publications and reports as the way forward to the development of mental health services and psychiatry.

Practical steps should be taken within the region to:

- Promote public enlightment regarding the nature of mental health and mental disorders, in spite of limited resources at our disposal. Partnerships with users and their families should be developed. The net effect of this approach will be an increase in the lobbyist power for more resources from the governments and other donor agencies as well as the communities themselves.

- Teaching of psychiatry is slow ly beginning to take shape, with several university departments of psychiatry coming up. Many of these offer excellent teaching. There is a need to pool resources and where possible encourage the development of centres of excellence, where neighbouring countries can send their graduates for further experience and training in specific areas such as research and psychopharmacology. The development of locally trained human resources should gradually create a critical mass of know led geable professionals who with further encouragement and resource availability should be able to develop indigenous research programmes and so on. Similarly, collaborative research activities should be promoted among the professionals and departments of psychiatry in Africa.

- Lobbying for adequate funding from governments and NGOS has to be done aggressively. The increase in resource allocation and prioritisation for mental health among health policy makers should ensure sustainability and availability of effective psychotropic drugs and their even distribution between rural and urban communities. The services should achieve a balance between community- and hospital-based mental health care with further integration of mental health in primary health care, based on planned and strategically achievable interventions within the available resources.

\section{Fred Kigozi}

President, U ganda Psychiatric Association WPA Zone 14, Zonal Representative 